\title{
Microencapsulation of DHA Algal Oil by Spray Drying
}

\author{
Wenyao SHAO* \\ Department of Chemical and Biochemical Engineering \\ Xiamen University \\ Xiamen 361005, Fujian, PR China \\ e-mail:wyshao@xmu.edu.cn
}

\author{
Quanling XIE \\ Engineering Research Center of Marine Biological \\ Resource Comprehensive Utilization, SOA \\ The Third Institute of Oceanography of the State Oceanic \\ Administration \\ Xiamen 361005, Fujian, PR China \\ e-mail: qlxie@tio.org.cn
}

\author{
Mengwen YAN \\ Department of Chemical and Biochemical Engineering \\ Xiamen University \\ Xiamen 361005, Fujian, PR China \\ e-mail:mwyan@stu.xmu.edu.cn
}

\author{
Xueshan PAN \\ Department of Chemical and Biochemical Engineering \\ Xiamen University \\ Xiamen 361005, Fujian, PR China \\ e-mail: panxueshan@xmu.edu.cn
}

\begin{abstract}
The aim of this study is to evaluate and optimize the influence of process conditions on the microencapsulation of DHA algal oil by spray drying, while using whey protein isolate (WPI) and maltodextrin (MD) as wall material. Emulsion stability was analyzed. Microencapsulation efficiency, surface oil content and moisture content are evaluated with the change of five independent variables, including the ratio of WPI and $\mathrm{MD}$, the ratio of core and wall material, total solid content, inlet air temperature and centrifugal disk speed. The morphology of the microcapsules was observed using scanning electron microscopy (SEM). Particle size distribution was measured using high Resolution Laser Particle Size Analyzer. The microencapsulation process was finally optimized at 2.5 of WPI/MD, 0.2 of core/wall material, 0.5 of total solid content, inlet air temperature of $180^{\circ} \mathrm{C}$ and centrifugal disk speed of $32000 \mathrm{rpm}$. The produced microcapsules with spherical shape exhibited smooth and free of pores, cracks and surface indentation, which indicated the emulsification and encapsulation of DHA with above process was feasible.
\end{abstract}

Keywords-microencapsulation; DHA algal oil; spray drying; process condition evaluation

\section{INTRODUCTION}

Docosahexaenoic acid (DHA), usually referring as brain gold, is an important member of the Omega-3 polyunsaturated fatty acids family. DHA occurs naturally as a cell membrane fatty acid in the brain, retina, testes, and sperm, and is essential in the development of these organs and cells $[1,2]$. It has been reported that this important component containing up to $20 \%$ in the human cerebral cortex, and accounting for about $50 \%$ in the retina of eyes. However, because of the presence of unsaturated bonds in molecular structure (Fig.1), DHA is susceptible to oxidants, light and heat, which can be easily deteriorated when exposed to such factors. Therefore, the free DHA must be protected in some forms before its industrial application.

In food processing field, microencapsulation technique has been widely used to protect food ingredients against deterioration, volatile losses, or premature interaction with other ingredients. The protective mechanism is to form a membrane (wall system) to enclose droplets or particles of the encapsulated material (core) [3]. So far, various kinds of microencapsulation techniques such as solvent dispersion, phase separation, co-crystallization, interfacial polymerization etc., have been developed, among which, spray-drying is the most commonly used one in the food industry due to its continuous production and easiness of industrialization [4, 5].

Carbohydrates such as starches, maltodextrins, corn syrup solids and acacia gums have been extensively used as encapsulating agents $[6,7]$. These materials have many of the properties desirable in an encapsulating agent such as low viscosity at high solids contents and good solubility, most lack the interfacial functionality associated with encapsulation materials such as milk proteins [8, 9]. However, the high cost of milk proteins in comparison with carbohydrates is disadvantageous. As no single wall material possesses all the properties required of an ideal encapsulating agent, approaches to improve encapsulating properties have focused on blends of carbohydrate and protein $[10,11]$ or on chemical modification of carbohydrates in order to confer surface active properties [12, 13]. In this study, we chose whey protein isolate (WPI) and maltodextrin (MD) as mixed composite wall materials to encapsulate DHA algal oil, and the emulsification and encapsulation process of DHA were investigated to obtain the optimal process conditions.

Figure 1. Docosahexaenoic acid ( DHA) (22:6)

\section{MATERIALS AND MethodS}

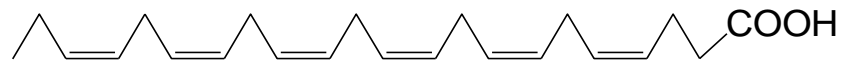

A. Materials

Wall materials include whey protein isolate and maltodextrin were both purchased from Shandong Xiwang Biochemical technology co., Ltd, China. DHA algal oil 
( $\geq 40 \%$ ) was supplied by Xiamen Huison Biotech Co., Ltd, China. All chemicals used were of food grade.

\section{B. Preparation of Emulsions}

Whey protein isolate and maltodextrin were dissolved in hot distilled water $\left(75^{\circ} \mathrm{C}\right)$ with different ratio, being stirred for $15 \mathrm{~min}$, to form aqueous wall solution. Coarse emulsions were prepared by blending DHA algal oil and the wall solution, using a high shear emulsifying machine (Ultra-turrax IKA T25 Basic, GER) operating at 13,000 rpm for $5 \mathrm{~min}$.

\section{Emulsions Stability Analysis}

Take $20 \mathrm{ml}$ of emulsion, which was prepared by blending the DHA algal oil and the wall solution, into analysis bottle, and put the bottle in a high shear emulsifying machine (Ultra-turrax IKA T25 Basic, GER) operating at 13,000 rpm for $5 \mathrm{~min}$. Then, use to a full-featured stable instrument (TURBISCAN LAB, French FORMULACTION Co., France) under a constant temperature of $50^{\circ} \mathrm{C}$ for emulsion stability analysis.

\section{Preparation of Microcapsules}

The resulting emulsion was then spray-dried on a Model GZ-5 Spray Dryer (Wuxi city sunshine dryer Equipment Factory, Jiangsu, China) equipped with a spry-drying chamber with dimensions of $210 \mathrm{~cm}$ height and $65 \mathrm{~cm}$ diameter, a high speed centrifugal atomizer, a cyclone separator, plus a hot air blower and a exhaust blower. The emulsion was fed into the chamber, the feed rate was 34 $\mathrm{ml} / \mathrm{min}$, atomized by the hot air from blower in a co-current flow mode and the spray-dried microcapsules were collected in the cyclone separator driven by the exhaust blower.

\section{E. Microapsules Characterization}

1) Microencapsulation efficiency: One of the important quality parameters in encapsulation of oils by spray drying is microencapsulation efficiency (ME), which is the percentage of encapsulated oil in total oil. The ME is commonly determined indirectly by extracting unencapsulated oil (free oil) present on the surface of microcapsules through washing powders with an organic solvent [14]. (Eq. (1)).

$$
\mathrm{E}(\%)=\frac{\mathrm{M}_{\mathrm{t}}-\mathrm{M}_{\mathrm{s}}}{\mathrm{M}_{\mathrm{t}}} \times 100
$$

Where $\mathrm{M}_{\mathrm{t}}$ is the total amount of oil and $\mathrm{M}_{\mathrm{s}}$ is the amount of non-encapsulated oil presented in the surface of microcapsules.

The non-encapsulated oil present in the particle surface was determined in the following method [15]. Typically, surface oil was measured by adding $20 \mathrm{ml}$ of petroleum ether $\left(30-60^{\circ} \mathrm{C}\right)$ to $3 \mathrm{~g}$ of powder and shaking with a constant temperature shaker (SKY-100C, Shanghai SuKun industrial co., LTD, Shanghai, China) for 2 min with shaken speed of $200 \mathrm{rpm}$ at room temperature. The solvent mixture was then filtered through a filter paper and the collected powder on the filter was rinsed three times with $20 \mathrm{ml}$ of petroleum ether $\left(30-60^{\circ} \mathrm{C}\right)$. The filtrate solution containing the extracted oil was transferred to a clean beaker, which was left to evaporate and then was dried at $105 \mathrm{C}$ until constant weight. The surface oil was calculated based on the difference between the initial clean beaker and that containing the extracted oil residue [16].

2) Surface oil content: Surface oil content was calculated as follows (Eq.2):

$$
\text { Surface oil content }(\%)=\frac{\mathrm{W}_{\mathrm{s}}}{\mathrm{W}_{0}} \times 100
$$

Where $\mathrm{W}_{\mathrm{s}}$ is the weight of surfce oil on the sample and $\mathrm{W}_{0}$ is the weight of original dry status sample.

3) Moisture content: Moisture content was determined gravimetrically by oven drying at $105^{\circ} \mathrm{C}$ to constant weight. Approximately $5 \mathrm{~g}$ of the dry status sample was put in an air oven at $105^{\circ} \mathrm{C}$ for $3 \mathrm{~h}$. The moisture content was calculated by the following equations (Eq.3):

$$
\text { Moisture (\%) }=\frac{\mathrm{W}_{0}-\mathrm{W}_{1}}{\mathrm{~W}_{0}} \times 100
$$

Where $\mathrm{W}_{0}$ is the weight of original dry status sample and $\mathrm{W}_{1}$ is the weight of sample after oven treatment.

4) Particle morphology: The particle was observed on scanning electron microscope (SEM) (S-4800, Japan Hitachi, Ltd, Japan) for evaluation of their particle size and outer surface. A small amount of spray-dried DHA algal oil microcapsules were placed on one surface of a double-faced adhesive tape that stick to the sample support, the sample specimens were subsequently coated with a thin layer of platinum for $60 \mathrm{~s}$ in a vacuum evaporator using a sputter coater (JFC-1600, Japan JEOL Ltd, Japan) before it can be seen by SEM.

5) Particle size distribution: The particle size distribution was measured using a high Resolution Laser Particle Size Analyzer, Saturn DigiSizer 5200 (Micromeritics Instrument Corporation, Norcross, USA). $3 \mathrm{~g}$ powder sample was dispersed in $15 \mathrm{ml} \mathrm{99.7 \%} \mathrm{ethanol} \mathrm{and}$ the particle distribution was monitored during three successive readings. The particle size was expressed as the mean volumetric size $d_{43}$ (De Brouckere mean diameter), which is the mean diameter of a sphere with the same volume, and is generally used to characterize a particle. Ethanol (99.7\%) was used as the dispersing medium.

\section{F. Microencapsulation Performance Analysis}

This study was used to test the performance of WPI and MD in microencapsulation of DHA algal oil, considering five independent variables: the ratio of WPI and MD, the ratio of core and wall material, total solid content, inlet air temperature and centrifugal disk speed. Microencapsulation efficiency, surface oil content and moisture content of particles were further examined with the change of five variables, and were used to determine the microencapsulation performance. 


\section{RESUlTS AND DisCUSSIONS}

\section{A. Emulsion Stability Analysis}

Emulsion stability, in terms of flocculation, coalescence or phase separation, has been reported to have an influence on microencapsulation efficiency; stability and properties of spray dried oil powders [17]. Therefore, after preparation of the emulsion it must remain stable during the spray drying process. In the present study, the time taken to complete the spray drying process for one batch after emulsion preparation was 30-40 min [15].

We compared three different kinds of emulsions with different ratio of core and wall material (Fig.2), the stability index of the second sample was lower than the others from the beginning to the compare time of around $7.5 \mathrm{~h}$, for example, at $45 \mathrm{~min} 57 \mathrm{~s}$, the stability index of the second sample was 4.90 , it was the lowest of all (others were 6.05 and 7.02 respectively). The stability index represented the variation of transmission and backscattering signals [18], the smaller the stability index, the more stable the emulsion. At the same time, microencapsulation efficiency was the highest at 0.2 of core and wall material (Table III). Consequently, the ratio of core and wall material we chose was 0.2 .

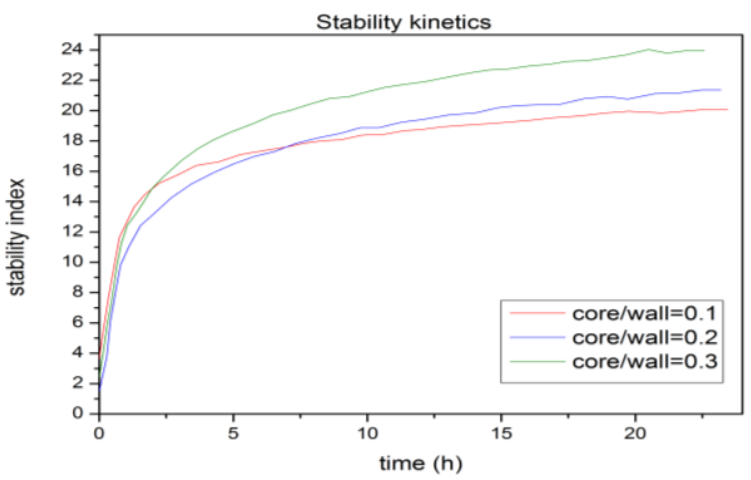

Figure 2. Stability kinetics of three kinds of emulsions above ( 2.5 of WPI/MD, 0.3 of total solid content, the ratio of core and wall material was $0.1,0.2,0.3$, respectively).

\section{B. Particle Morphology}

The SEM images of the spray-dried microencapsulation of DHA algal oil are shown in Fig.3. It could be found that microencapsulation of DHA algal oil showed a spherical shape with $20-80 \mu \mathrm{m}$ in diameter, and a smooth surface. Some of them had small holes which had a bad effect for the embedded oil, the ME and surface oil content would decrease as a result of the embedded DHA algal oil diffusion to the surface. The formation of smooth surface were probably attributed to the addition of MD in the formulation, which could retain some water molecules linked to its own structure, filling the intern empty space of the microparticles, preserving the hydration, avoiding depressions on the surface, and thus assuring a more uniform and smooth wall of the obtained icroparticles [3, 19].

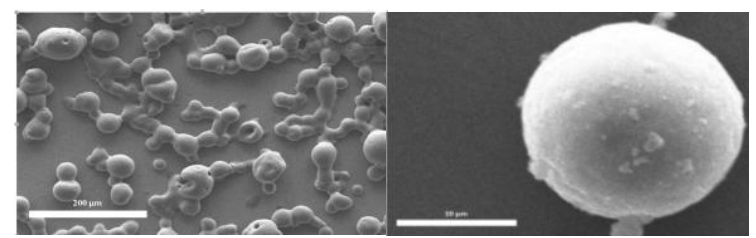

Figure 3. SEM images of the DHA microcapsules (2.5 of WPI/MD, 0.4 of core/ wall material, 0.3 of total solid content, $32000 \mathrm{rpm}$ of centrifugal disk speed and $160^{\circ} \mathrm{C}$ of inlet air temperature).

\section{Particle Size Distribution}

Size distributions of microencapsulation of DHA algal oil prepared at different ratios of WPI and MD (with 0.2 of core and wall material, 0.3 of total solid content, $160^{\circ} \mathrm{C}$ of inlet air temperature, 32000rpm of centrifugal disk speed). Only the ratio of WPI/MD is changed, the other four variables (core and wall material, total solid content, inlet air temperature, centrifugal disk speed) remain unchanged.

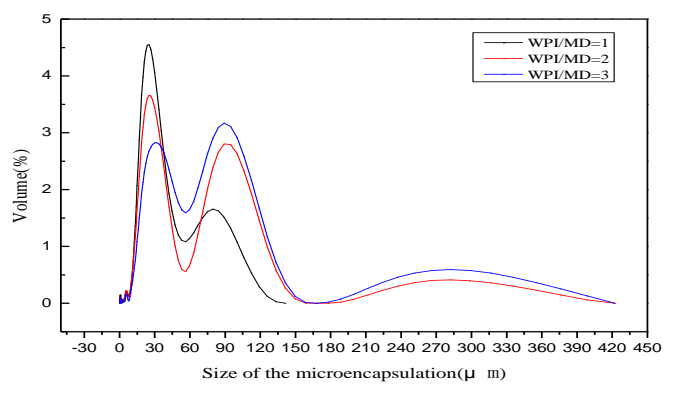

Figure 4. Particle size distribution of powers produced with different ratios of WPI and MD ( 0.2 of core and wall material, 0.3 of total solid content, $160{ }^{\circ} \mathrm{C}$ of inlet air temperature, and $32000 \mathrm{rpm}$ of centrifugal disk speed).

From Fig. 4, it is possible to notice that some distribution curves presented bimodal behavior (with two different peaks), while others showed three distinct peaks. The first peak corresponds to a mean particle diameter of approximately $30 \mu \mathrm{m}$, whereas the second peak corresponds to a mean diameter around $100 \mu \mathrm{m}$, the third peak approaches $280 \mu \mathrm{m}$. This can be particularly interesting in the case of powders, since the population of smaller particles can penetrate into the spaces between the larger ones, thus occupying less space. The presence of larger particles $(100-420 \mu \mathrm{m})$ could be associated to a beginning of agglomeration, due to the formation of irreversible link bridges. The presence of such bonds could be related to the free oil found at the particles surface [20]. The powders' corresponding mean diameters $\left(\mathrm{d}_{43}\right)$ were 33.439 , 37.587, $63.641 \mu \mathrm{m}$ (with the ratio of WPI/MD 1, 2, 3). Powders with small particle would agglomerate easily, and they had poor wettability and dispersibility, so we chose 2.5 of WPI/MD combining their ME and surface oil content.

\section{Microencapsulation Performance Analysis}

1) The ratio of WPI and MD: Table I shows the influence of the ratio of WPI and MD on the properties of DHA algal oil microencapsulation. The ME increased from 
$48.28 \%$ to $76.56 \%$ on the different ratios of WPI and MD. Young et al. [8] showed that the ME values of spray dried powders encapsulating anhydrous milk fat were inversely proportional to the ratio of WPI-to-carbohydrate, that is the free fat content decreased as the proportion of WPI-to-carbohydrates decreased and also when a mixture of WPI and carbohydrates was used as wall materials other than WPI alone. In the study by Bae et al. [15], such a trend that could be attributed to either the emulsion droplet size or the ratio of WPI to MD was not obtained. We chose the special one (the ratio of WPI and MD was 2.5), because its ME was the highest of all, surface oil content was the lowest and moisture content was not high.

Moisture content varied from $1.39 \%$ to $2.76 \%$ when the WPI/MD ratio changed from 1 to 3 . Although moisture content was the highest at the WPI/MD ratio of 2.5 , the ME was high and surface oil content was low at this condition. So we still chose 2.5 the ratio of WPI/MD.

TABLE I. INFLUENCE OF THE RATIO OF WPI AND MD ON THE PROPERTIES OF DHA ALGAL OIL MiCROENCAPSULATION

\begin{tabular}{|c|c|c|c|}
\hline $\begin{array}{c}\text { WPI/MD } \\
\text { ratio(w/w) }\end{array}$ & $\begin{array}{c}\text { Microencapsul } \\
\text { ation } \\
\text { efficiency }(\%)\end{array}$ & $\begin{array}{c}\text { Surface oil } \\
\text { content (\%) }\end{array}$ & $\begin{array}{c}\text { Moisture } \\
\text { content (\%) }\end{array}$ \\
\hline 1 & 53.85 & 7.69 & 2.14 \\
\hline 1.5 & 54.29 & 7.62 & 1.78 \\
\hline 2 & 48.28 & 8.62 & 1.39 \\
\hline 2.5 & 76.56 & 3.91 & 1.61 \\
\hline 3 & 48.57 & 8.57 & \\
\hline
\end{tabular}

2) The ratio of core and wall material: Table II shows the influence of the ratio of core and wall material on the properties of DHA algal oil microencapsulation. The ratio of core and wall material was the factor that affected the ME, showing a negative effect on this response. The higher the ratio of core and wall material (0.2-0.5), the lower the $\mathrm{ME}$ was, the higher the surface oil content. Huynh et al. [21] observed the same behaviors in the microencapsulation of lemon myrtle oil, using modified starch, maltodextrin and whey protein concentrate, maltodextrin as wall materials. According to Minemoto et al. [22], the ME decreased when the weight ratio of core to wall material increased.The effect of the ratio of core and wall material on the ME may be related to the emulsion droplet size, which was lower for higher ratio of core and wall material. Many studies have shown that the microencapsulation efficiency of oils and flavors is improved with decreasing emulsion droplet size $[16,23]$.

The ratio of core and wall material showed a little effect on moisture content. It was $2.36 \%$ to $3.04 \%$, the lowest moisture content was observed in the powders produced with 0.3 of the ratio of core and wall material, which can be attributed to higher hydrophobicity of these powders. Dian et al. [24] found moisture content values varying from $2.2 \%$ to $3.0 \%$ for microencapsulated palm oil and observed that this property was not affected by the oil amount and the type of wall material. It was also found that moisture content was not affected by type of wall material or core/wall material ratio.

TABLE II. INFLUENCE OF THE RATIO OF CORE AND WALL MATERIAL ON THE PROPERTIES OF DHA AlgAL OIL MiCROENCAPSULATION

\begin{tabular}{|c|c|c|c|}
\hline $\begin{array}{c}\text { Core/Wall } \\
\text { material } \\
\text { ratio(w/w) }\end{array}$ & $\begin{array}{c}\text { Microencaps } \\
\text { ulation } \\
\text { efficiency } \\
(\%)\end{array}$ & $\begin{array}{c}\text { Surface oil } \\
\text { content }(\%)\end{array}$ & $\begin{array}{c}\text { Moisture } \\
\text { content (\%) }\end{array}$ \\
\hline 0.1 & 71.01 & 2.63 & 3.04 \\
\hline 0.2 & 76.56 & 3.91 & 2.76 \\
\hline 0.3 & 68.84 & 7.19 & 2.36 \\
\hline 0.4 & 58.14 & 11.96 & 2.97 \\
\hline 0.5 & 50.00 & 16.67 & 2.63 \\
\hline
\end{tabular}

3) Total solid content: Table III shows the influence of total solid content on the properties of DHA algal oil microencapsulation. Total solid content had a positive effect on the ME, the increase in total solid content resulted in higher ME and lower surface oil content. When increasing total solid content from 0.1 to 0.5 , the ME increased from $54.03 \%$ to $88.24 \%$ and the surface oil content decreased from $7.66 \%$ to $1.96 \%$, respectively. Higher total solid content implies in shorter time to form a crust, making difficult the oil diffusion to the drying particle surface. Moreover, increasing total solid content leads to the increase of emulsion viscosity, reducing the circulation movements inside the droplets and, thus, resulting in a rapid skin formation and a higher ME [16]. The higher ME shown by particles produced from emulsions with higher total solid content may also be attributed to the emulsion droplets size, because increasing total solid content led to the production of droplets with lower diameters. As previously discussed, the smaller the emulsion droplet, the higher the ME, which explains the results obtained. Many studies have certificated that lower emulsion droplet size leads to higher ME of oils and flavours [16, 23]. Tonon et al. [25] also verified that the encapsulation efficiency was influenced by total solid content from the study of the microencapsulation of flaxseed oil using gum Arabic as wall material.

Total solid content also affected the particle moisture content. Moisture content decreased when the solid content increased up to 0.2 , while for solid content between 0.2 and 0.3 , total solid content had a positive effect on particle moisture content, at last when the total solid content exceeded 0.3 , moisture content decreased when the solid content increased up to 0.5.The increase in the total solid concentration means higher viscosity and less water 
available for evaporation, resulting in lower moisture content. However, for solid concentrations above 0.2 , the increase in emulsion viscosity may have reduced water diffusion, resulting in powders with higher moisture content. When the total solid content exceeded 0.3 , we thought the higher viscosity and less water available for evaporation resulted lower moisture content.

TABLE III. INFLUENCE OF THE TOTAL SOLID CONTENT ON THE PROPERTIES OF DHA ALGAL OIL MicROENCAPSULATION

\begin{tabular}{|c|c|c|c|}
\hline $\begin{array}{c}\text { Total solid } \\
\text { content }\end{array}$ & $\begin{array}{c}\text { Microencapsul } \\
\text { ation } \\
\text { efficiency (\%) }\end{array}$ & $\begin{array}{c}\text { Surface oil } \\
\text { content (\%) }\end{array}$ & $\begin{array}{c}\text { Moisture } \\
\text { content (\%) }\end{array}$ \\
\hline 0.1 & 54.03 & 7.66 & 1.87 \\
\hline 0.2 & 56.72 & 7.21 & 0.49 \\
\hline 0.3 & 76.56 & 3.91 & 2.76 \\
\hline 0.4 & 78.12 & 3.64 & 0.97 \\
\hline 0.5 & 88.24 & 1.96 & 0.50 \\
\hline
\end{tabular}

4) Inlet air temperature: Table IV shows the influence of the inlet air temperature on the properties of DHA algal oil microencapsulation. Increasing inlet air temperature from 160 to $190^{\circ} \mathrm{C}$ while keeping other parameters unchanged, the $\mathrm{ME}$ increased with temperature at first, but then decreased when temperature reached $190^{\circ} \mathrm{C}$, surface oil content had the opposite behavior. The high inlet temperature may break the balance between the rate of water evaporation and film-formation, leading wall system of microcapsules broken down, and thus a low ME. Lycopene could easily decomposite when exposed directly to heat, therefore, it is rational to deduce that a low ME could be obtained when most of the microcapsules were broken [3]. When inlet air temperature reached $190^{\circ} \mathrm{C}$, the $\mathrm{ME}$ decreased, surface oil content increased. The decrease in the ME with the increase of temperature could be related to the fact that higher inlet air temperatures affect the balance between the water evaporation rate and the film formation, leading to a breakdown of the crust. In other words, high temperatures promote a faster drying of the external area, as compared to the internal one, which creates cracks in the particle wall, resulting in oil release.

The increase in inlet air temperature up to $170^{\circ} \mathrm{C}$ led to a reduction of moisture content. Frascareli et al. [20] had noted that when high temperatures are used, there is a large temperature gradient between the atomized product and the drying air, resulting in greater heat and mass transfer, consequently, in greater water evaporation rates. The reduction of powder moisture content with increasing inlet air temperature was also observed in spray dried pure sweet potato [26], watermelon pulp [27] and antocyanin pigments [28]. However, for temperatures above $170^{\circ} \mathrm{C}$, the increase in drying temperature led to an increase on particle moisture content.
TABLE IV. INFLUENCE OF THE INLET AIR TEMPERATURE ON THE PROPERTIES OF DHA

\begin{tabular}{|c|c|c|c|}
\hline $\begin{array}{c}\text { Inlet air } \\
\text { temperature } \\
\left({ }^{\circ} \mathrm{C}\right)\end{array}$ & $\begin{array}{c}\text { Microencapsulation } \\
\text { efficiency }(\%)\end{array}$ & $\begin{array}{c}\text { Surface oil } \\
\text { content }(\%)\end{array}$ & $\begin{array}{c}\text { Moisture content } \\
(\%)\end{array}$ \\
\hline 150 & 96.02 & 0.67 & 0.79 \\
\hline 160 & 88.24 & 1.96 & 0.50 \\
\hline 170 & 90.05 & 1.66 & 0.43 \\
\hline \hline 180 & 94.14 & 0.98 & 0.44 \\
\hline \hline 190 & 88.24 & 1.96 & 1.45 \\
\hline
\end{tabular}

5) Centrifugal disk speed: Table V shows the influence of the centrifugal disk speed on the properties of DHA algal oil microencapsulation. The centrifugal disk speed illustrated a little effect on the ME and surface oil content, the ME changed from $92.13 \%$ to $94.17 \%$ and surface oil content varied from $0.97 \%$ to $1.31 \%$. As considering the machine's maximum centrifugal disk speed was $40000 \mathrm{rpm}$, we decided to use the $32000 \mathrm{rpm}$ as the optimal choice.

Moisture content changed from $0.44 \%$ to $1.46 \%$, while for the centrifugal disk speed between $24000 \mathrm{rpm}$ and 40000 rpm. Centrifugal disk speed varied from $24000 \mathrm{rpm}$ to 28000 rpm, moisture content increased from $0.98 \%$ to $1.46 \%$ at first, moisture content was the lowest at the centrifugal disk speed of $32000 \mathrm{rpm}$, and then moisture content increased when the centrifugal disk speed increased up to $40000 \mathrm{rpm}$ at last. Centrifugal disk speed changed from $28000 \mathrm{rpm}$ to 32000 rpm, particle diameter became smaller, and it meant less water available for evaporation, resulting in lower moisture content. However, for centrifugal disk speed above 32000 $\mathrm{rpm}$, the decrease in particle diameter may have reduced water diffusion, resulting in powders with higher moisture content.

TABLE V. INFLUENCE OF THE CENTRIFUGAL Disk SPEED ON THE PROPERTIES OF DHA ALGAL OIL MICROENCAPSULATION

\begin{tabular}{|c|c|c|c|}
\hline $\begin{array}{c}\text { Centrifugal } \\
\text { disk speed } \\
(\mathrm{rpm})\end{array}$ & $\begin{array}{c}\text { Microencapsulation } \\
\text { efficiency (\%) }\end{array}$ & $\begin{array}{c}\text { Surface oil } \\
\text { content (\%) }\end{array}$ & $\begin{array}{c}\text { Moisture } \\
\text { content (\%) }\end{array}$ \\
\hline 24000 & 94.00 & 1.00 & 0.98 \\
\hline 28000 & 92.13 & 1.31 & 1.46 \\
\hline 32000 & 94.14 & 0.98 & 0.44 \\
\hline 36000 & 94.17 & 0.97 & 1.02 \\
\hline 40000 & 94.04 & 0.99 & 1.45 \\
\hline
\end{tabular}




\section{CONCLUSIONS}

Microencapsulation of DHA algal oil was successfully prepared by a spray-drying method using a wall system consisting of WPI and MD. The ME, surface oil content and moisture content were influenced by the ratio of WPI and $\mathrm{MD}$, the ratio of core and wall material, total solid content, inlet air temperature, and the centrifugal disk speed. The microencapsulation process was optimized at 2.5 of WPI /MD, 0.2 of core and wall material, 0.5 of total solid content, $180^{\circ} \mathrm{C}$ of inlet air temperature and centrifugal disk speed of 32000rpm. Emulsion stability analysis demonstrated the emulsion stability was worse than the emulsion after a two-step emulsification, but in the present study, the time taken to complete the spray drying process for one batch after emulsion preparation was about 30-40 min during which the migration of particles from the bottom to the top was not that bad and the stability index was low.

SEM analysis demonstrated that some of the microcapsules had a smooth surface, a regular spherical shape, some of them had an irregular shape, and DHA algal oil was embedded in the wall system consisting of WPI and MD. Particle size distribution shown that the microcapsules we produced had a wide range of particle size distribution $(0.399-422.317 \mu \mathrm{m})$ which is a typical characteristic of spray dried powders. This article would promote the development of the applications of the DHA algal oil.

\section{ACKNOWLEDGMENT}

The author gratefully acknowledges the financial support of Natural Science Foundation Youth Fund of China (No. 21406185).

\section{REFERENCES}

[1] M. Hsia, R. Mavis, J. De Sesso, Health effects of refined menhaden oil, Prepared by Mitre Corp., Civil Systems Division, McLean, Virginia for US Food and Drug Administration (US FDA), Washington, DC (PB89-182398), (1989).

[2] M.C. Linder, Nutritional biochemistry and metabolism: with clinical applications, Elsevier1991.

[3] B. Shu, W. Yu, Y. Zhao, X. Liu, Study on microencapsulation of lycopene by spray-drying, Journal of Food Engineering, 76 (2006) 664-669.

[4] M. Jimenez, H. Garcia, C. Beristain, Spray-drying microencapsulation and oxidative stability of conjugated linoleic acid, European Food Research and Technology, 219 (2004) 588-592.

[5] M. Rodríduez-Huezo, R. Pedroza-Islas, L. Prado-Barragán, C. Beristain, E. Vernon-Carter, Microencapsulation by spray drying of multiple emulsions containing carotenoids, Journal of Food Science, 69 (2004) 351-359.

[6] F. Thevenet, Acacia gums: Stabilizers for flavor encapsulation, ACS Symposium series-American Chemical Society (USA), 1988.

[7] M.M. Kenyon, Modified starch, maltodextrin, and corn syrup solids as wall materials for food encapsulation, (1995).

[8] S. Young, X. Sarda, M. Rosenberg, Microencapsulating properties of whey proteins. 1. Microencapsulation of anhydrous milk fat, Journal of Dairy Science, 76 (1993) 2868-2877.

[9] D. Moreau, M. Rosenberg, Oxidative stability of anhydrous milkfat microencapsulated in whey proteins, Journal of Food Science, 61 (1996) 39-43.
[10] P. Fäldt, B. Bergenståhl, The surface composition of spray-dried protein-lactose powders, Colloids and Surfaces A: Physicochemical and Engineering Aspects, 90 (1994) 183-190.

[11] T.Y. SHEU, M. Rosenberg, Microencapsulation by spray drying ethyl caprylate in whey protein and carbohydrate wall systems, Journal of Food Science, 60 (1995) 98-103.

[12] W.E. Bangs, G.A. Reineccius, Corn starch derivatives: possible wall materials for spray-dried flavor manufacture, ACS Symposium series American Chemical Society, 1988.

[13] P. Trubiano, N. Lacourse, Emulsion-stabilizing starches: use in flavor encapsulation, ACS Symposium series-American Chemical Society (USA), 1988.

[14] J. Velasco, C. Dobarganes, G. Márquez-Ruiz, Variables affecting lipid oxidation in dried microencapsulated oils, Grasas y aceites, 54 (2003) 304-314.

[15] E. Bae, S. Lee, Microencapsulation of avocado oil by spray drying using whey protein and maltodextrin, Journal of Microencapsulation, 25 (2008) 549-560

[16] S.M. Jafari, E. Assadpoor, Y. He, B. Bhandari, Encapsulation efficiency of food flavours and oils during spray drying, Drying Technology, 26 (2008) 816-835.

[17] L. Tan, L. Chan, P. Heng, Effect of oil loading on microspheres produced by spray drying, Journal of Microencapsulation, 22 (2005) 253-259.

[18] C. Celia, E. Trapasso, D. Cosco, D. Paolino, M. Fresta, Turbiscan Lab® Expert analysis of the stability of ethosomes ${ }^{\circledR}$ and ultradeformable liposomes containing a bilayer fluidizing agent, Colloids and Surfaces B: Biointerfaces, 72 (2009) 155-160.

[19] M. Bruschi, M. Cardoso, M. Lucchesi, M. Gremião, Gelatin microparticles containing propolis obtained by spray-drying technique: preparation and characterization, International Journal of Pharmaceutics, 264 (2003) 45-55.

[20] E. Frascareli, V. Silva, R. Tonon, M. Hubinger, Effect of process conditions on the microencapsulation of coffee oil by spray drying, Food and bioproducts processing, 90 (2012) 413-424.

[21] T.V. Huynh, N. Caffin, G.A. Dykes, B. Bhandari, Optimization of the microencapsulation of lemon myrtle oil using response surface methodology, Drying Technology, 26 (2008) 357-368.

[22] Y. Minemoto, K. Hakamata, S. Adachi, R. Matsuno, Oxidation of linoleic acid encapsulated with gum arabic or maltodextrin by spray-drying, Journal of Microencapsulation, 19 (2002) 181-189.

[23] A. Soottitantawat, F. Bigeard, H. Yoshii, T. Furuta, M. Ohkawara, P. Linko, Influence of emulsion and powder size on the stability of encapsulated D-limonene by spray drying, Innovative Food Science \& Emerging Technologies, 6 (2005) 107-114.

[24] N.L.H.M. Dian, N.a. Sudin, M.S.A. Yusoff, Characteristics of microencapsulated palm-based oil as affected by type of wall material, Journal of the Science of Food and Agriculture, 70 (1996) 422-426.

[25] R.V. Tonon, C.R. Grosso, M.D. Hubinger, Influence of emulsion composition and inlet air temperature on the microencapsulation of flaxseed oil by spray drying, Food Research International, 44 (2011) 282-289.

[26] J. Grabowski, V.D. Truong, C. Daubert, Spray-Drying of Amylase Hydrolyzed Sweetpotato Puree and Physicochemical Properties of Powder, Journal of food science, 71 (2006) E209-E217.

[27] S.Y. Quek, N.K. Chok, P. Swedlund, The physicochemical properties of spray-dried watermelon powders, Chemical Engineering and Processing: Process Intensification, 46 (2007) 386-392.

[28] S. Ersus, U. Yurdagel, Microencapsulation of anthocyanin pigments of black carrot (Daucus carota L.) by spray drier, Journal of Food Engineering, 80 (2007) 805-812. 